Currículo sem Fronteiras, v. 20, n. 2, p. 372-394, maio/ago. 2020

\title{
FORMAÇÃO E ATUAÇÃO DE PROFESSORES DE TEATRO: PPCs, corpos e educação
}

\author{
Amanda Diniz Gonçalves \\ Universidade Federal do Tocantins - UFT \\ Juliano Casimiro de Camargo Sampaio
}

Universidade Federal do Tocantins - UFT

\begin{abstract}
Resumo
Neste artigo analisamos as reformulações de Projetos Político Pedagógicos de cinco cursos de Licenciatura em Teatro de Universidades Federais Brasileiras. O foco da pesquisa são as disciplinas que tem o corpo como objeto de estudos em criação e docência em teatro. Realizamos análise de documentos de duas naturezas: 1 - documentos oficiais que regimentam o ensino de arte e das linguagens artísticas no Brasil; 2 - Projetos Políticos Pedagógicos de cursos de Licenciatura de teatro, que foram reformulados nos anos de 2015 e 2016. Resulta da análise que são raras as articulações entre instrumentalização, criação e ensino de teatro, nas ementas e bibliografias utilizadas, com fins da preparação de professores para a educação básica brasileira (tomando-se os casos analisados como referência), bem como a ausência de quantitativo expressivo de obras de referência que tomem tal articulação como foco.
\end{abstract}

Palavras-Chave: Formação de Professores; Docência em Teatro; Licenciatura; Corpo; Ensino.

\begin{abstract}
In this article, we analyze the reformulations of Political Pedagogical Projects of undergraduate courses in Theater of Brazilian Federal Universities. The focus of the research are the disciplines that have the body as object of studies in creation and teaching in theater. We analyze documents of two natures: 1 - official documents that regiment the teaching of art and artistic languages in Brazil; 2 - Political Pedagogical Projects of undergraduate theater courses, which were reformulated in the years of 2015 and 2016. It turns out from the analysis that the articulations between instrumentalization, creation and theater teaching are rare, with the purpose of preparing teachers for Brazilian basic education, as well as the absence of significant quantitative reference works that take such articulation as focus.
\end{abstract}

Keywords: Education of teachers; Teaching of drama; Undergraduate; Body; Teaching. 


\section{Apresentação}

Este artigo é resultado de pesquisa de iniciação científica da primeira autora sob orientação do segundo autor, intitulada 'Mudanças nos Projetos Políticos-Pedagógicos das Licenciaturas em Teatro das Universidades Federais Brasileiras - O que muda nas relações sobre Corpo, Criação e Educação?'. Entre agosto de 2014 e julho de 2015 foi desenvolvido pelos autores deste texto outro projeto (pesquisa) de iniciação científica, anterior àquele, intitulado 'Corpo e construção de conhecimento: a experiência estética na formação dos professores de teatro'. Naquele primeiro momento,

(...) pretendíamos a verificação de como estão pensadas e explicitadas as relações entre corpo, criação teatral e educação em certas ementas e referências bibliográficas de disciplinas de curso de formação superior. A finalidade do estudo foi compreender o mapa conceitual e prático da formação dos futuros docentes em teatro sobre possíveis funções e naturezas para a inserção da experiência com teatro na escola. (Gonçalves \& Sampaio, 2016, p. 96).

Para a realização da primeira pesquisa, se fez necessário o levantamento de quais eram as Instituições Federais que ofertavam o curso de licenciatura em teatro, para que se tornasse possível compreender como estavam organizadas as ementas e bibliografias das disciplinas relativas ao estudo da relação entre corpo, criação e educação, presentes em seus Projetos Políticos-Pedagógicos de Curso (PPCs) das licenciaturas em teatro das Universidades Federais Brasileiras. Ao entrar em contato com as Instituições de Ensino Superior, para a realização da primeira etapa da pesquisa anterior, mais de $50 \%$ informaram aos pesquisadores em questão que, apesar de disponibilizarem os PPCs em vigor até então para o andamento da pesquisa, os mesmos estavam em processo de revisão e mudança, e que os novos PPCs entrariam em vigor entre janeiro de 2015 e janeiro de 2016.

Nessa direção, o segundo projeto de iniciação científica, de que este artigo é resultado, pretendeu analisar as mudanças propostas para as mesmas disciplinas já analisadas (disciplinas que focalizam as relações entre corpo, criação e educação), no que tange a mudanças conceituais (análise de ementas) e bibliográficas (bibliografia de referência). Pretendeu-se, ainda, discutir quais as implicações das mudanças propostas nos novos PPCs para a formação dos professores de teatro nessas instituições se comparado aos PPCs anteriormente em vigor. Manteve-se para as análises e discussões a premissa de que "É importante que o professor esteja consciente do teatro como um elemento fundamental na aprendizagem e desenvolvimento da criança e não como transmissão de uma técnica" (Brasil, 1997, p. 58). E

Foi por tomarmos como referência essa indicação presente nos Parâmetros Curriculares Nacionais sobre o ensino de teatro, bem como a premissa de que a inserção do teatro na escola atende, em grande medida, segundo o mesmo documento, à necessidade de ampliação das potencialidades corporais para contextos de expressão e comunicação, que optamos por centrar nossas pesquisas 
e análises nas relações entre corpo, criação e ensino, presentes nos Projetos Pedagógicos das licenciaturas em teatro. (Gonçalves \& Sampaio, 2016, p. 96).

Das 24 Universidades Federais que oferecem os cursos de Licenciatura em Teatro, obtiveram-se os seguintes quatro resultados:

1- Instituições que estavam em processo de reformulação, mas que não chegaram a implementar as mudanças no período da pesquisa: UNIFAP; UNIR; UFSM; UFRGS; UFPA; UFAC; UFU; UFSJ; UFMG; UFOP; UFT.

2- Instituições que alegaram não estarem em processo de reformulação: UFS.

3- Instituições de que não se obteve retorno: UFPE; UFPEL; UFC; UFPB; UFRN; UFMA; UFBA. Ainda que pudéssemos ter acesso aos documentos em sites de algumas dessas universidades, a conversa com o coordenador de curso era indispensável para que compreendêssemos a situação dos cursos. Sendo assim, só se debruçou sobre aquelas instituições com as quais se conseguiu efetivar contato.

4) Instituições que reformularam seus documentos no período focal desta pesquisa: UFAL; UFG; UFGD; UNB; UNIRIO.

Foram objetos de pesquisa na segunda etapa de investigação apenas as instituições que reformularam seus PPCs no período de janeiro de 2011 a janeiro de 2015 e implementaram os novos documentos entre janeiro de 2015 e janeiro de 2016 (tópico quatro dos resultados obtidos na primeira pesquisa citado acima). A consulta foi feita via e-mail, enviado aos coordenadores de cursos. Posteriormente, foram solicitados os dois PPCs (anterior e vigente) às Universidades que responderam positivamente à mudança em seus documentos. Cada documento foi individualmente consultado e analisado de forma comparativa sobre ementas e bibliografias implementadas e àquelas anteriormente em execução. Na direção já apontada, buscou-se compreender se as mudanças nos PPCs das instituições estudadas implicam em significativas mudanças para o pensamento e prática formativa na direção da interdependência entre corpo, criação e formação pessoal (educação), no contexto das aulas de teatro.

Pelo exposto, este artigo se vale de análise de casos múltiplos, a partir de abordagem descritiva e interpretativa de documentos institucionais oficiais (PPCs) e de revisão crítica de documentos legais para a formação e atuação em docência em teatro na Educação Básica Brasileira. As discussões dos resultados da pesquisa são de natureza qualitativa e se pautam em revisão crítica de literatura sobre a área.

O princípio norteador para a escolha dos documentos de análise se deu na medida do exposto na Resolução CNE/CP 2/2015 ${ }^{1}$ (p. 3), a saber:

$\S 20$ As instituições de ensino superior devem conceber a formação inicial e continuada dos profissionais do magistério da educação básica na perspectiva do atendimento às políticas públicas de educação, às Diretrizes Curriculares Nacionais, ao padrão de qualidade e ao Sistema Nacional de Avaliação da Educação Superior (Sinaes), manifestando organicidade entre o seu Plano de Desenvolvimento Institucional (PDI), seu Projeto Pedagógico Institucional (PPI) 
e seu Projeto Pedagógico de Curso (PPC) como expressão de uma política articulada à educação básica, suas políticas e diretrizes.

A análise se deu segundo os critérios a seguir:

1- Selecionaram-se para análise as disciplinas que faziam menção direta em seus títulos ao estudo do corpo, por exemplo: Corpo e Movimento; Ateliê Corporal; Expressão Corporal, Linguagem e Movimento etc.

2- As ementas foram analisadas de acordo com a constatação de possíveis 3 categorias de análise: 1- Instrumentalização; 2 - Criação; 3 - Ensino. A categoria instrumentalização foi construída a partir da evidenciação da presença das expressões: técnica, elementos técnicos, consciência corporal, domínio de postura, educação somática, consciência do movimento e derivações. Já a categoria criação foi organizada a partir da presença de expressões tais como: criação, movimento expressivo, construção de personagem, repertório de movimento, expressividade cênica, composição e derivações. A categoria ensino foi elaborada com fins de se encontrar nos documentos analisados referências diretas e explícitas com a futura atuação do professor de teatro na educação básica. Para tanto, partiu-se da busca por expressões como: educação, ensino, pedagogia, conhecimento e derivações.

3- As referências bibliográficas foram analisadas de acordo com a quantidade de aparições nas bibliografias das disciplinas e segundo a área de saber a que correspondiam.

No decorrer desse artigo será apresentado estudo individualizado de cada uma dessas cinco instituições que reformularam seus documentos no período focal desta pesquisa UFAL; UFG; UFGD; UNB; UNIRIO. Antes disso, entretanto, apresenta-se o histórico das legislações e práticas que culminaram no atual ensino de teatro na Educação Básica Brasileira.

\section{Ensino de Teatro no Brasil: como chegamos à "bacharelização"?}

A relação entre teatro e ensino de modo sistematizado, ainda que em abordagens e finalidades bem diversas das atuais, remonta à chegada dos jesuítas ao Brasil e ao processo europeu de 'educação' de indígenas (Almeida Junior, 2013). De fato, o mesmo se deu com outras linguagens artísticas, como a música, por exemplo (Martins, 2011). No século XX é a música e seu ensino que ganha maior destaque nas instituições escolares. De acordo com Martins (2011, p. 09),

(...) foi na Revolução de [19]30 que o ensino da música, dentro de um processo de controle e persuasão social, cresceu em importância nas escolas, passando a música a ser considerada um dos principais veículos de exaltação da nacionalidade, o que determinou sua difusão por todo país.

A música aparece já nos anos de 1930, por meio do canto orfeônico, nos currículos das escolas primárias e secundárias. Nos anos 30 e 40, Heitor Villa-Lobos institui a 
sistematização do Canto Orfeônico e com a lei de diretrizes e bases da educação nacional LDBN 4.024/61, institui-se a Educação Musical (Gomes \& Nogueira, 2008). "E a introdução da educação musical no Conservatório Brasileiro de Música e no Instituto Nacional de Música, com o objetivo de formar futuros músicos, ficaria a cargo de Liddy Chiaffarelli Mignone e Antônio Sá Pereira" (Martins, 2011, p. 09).

O desenho e os trabalhos manuais também compunham a presença da arte na educação básica (Brasil, 1997). Entretanto, essas atividades, assim como a Educação Musical, não eram consideradas como componentes curriculares independentes. Foi com a reforma de 1971, lei n. 5.692/71, que se incluiu a Arte (Educação Artística) no currículo escolar, considerada necessária na formação humana. Mesmo assim, as manifestações artísticas continuavam como atividades e não como disciplina obrigatória. Isto porque, a lei dividia o currículo da educação básica em disciplinas e atividades (Pimenta, 2016). Como afirma Pimenta (2013), foi a partir de então que se reconheceu a necessidade da formação de professores para a área de arte. Até aquele momento, as escolas se adaptaram para o oferecimento de atividades artísticas a partir dos capitais humanos que já possuem em seus quadros de colaboradores (Gomes \& Nogueira, 2008).

As licenciaturas são então pensadas a partir das estruturas dos bacharelados, compreendendo-se um ano a mais na formação, cujas matérias obrigatórias para a formação de professores eram: psicologia da educação; didática; elementos da administração escolar; prática de ensino na matéria de habilitação (estágio supervisionado) (Junqueira \& Manrique, 2015). Ainda que a formação específica para o professor de arte ganhe vulto no Brasil a partir da lei de 1971, já em 1961 a lei no 4042 estipulava a separação entre cursos de licenciatura e de bacharelado. Como afirma Martins (2011, p. 18), desde Del Ben (2009), "a exigência da licenciatura não é um mero capricho dos legisladores; ela reflete a preocupação com a profissionalização da docência e com a formação adequada daqueles que irão atuar nas escolas de educação básica".

Contudo, em Arte, como em muitas outras formações de professores no Brasil, o modelo adotado pelas licenciaturas foi o 3+1, três anos de formação técnica específica (provenientes dos conteúdos do bacharelado) e um ano de formação pedagógica (Pimenta, 2013). Segundo a autora, na década de 1970 surgem as licenciaturas curtas para a formação do professor de arte. Formação essa voltada para a atuação polivalente das linguagens artísticas. Nos anos seguintes, as licenciaturas curtas passam a ser substituídas pelas licenciaturas plenas, com habilitações específicas nas diferentes linguagens artísticas. Com a LDB de 1996 as licenciaturas curtas deixam de ser oferecidas nas instituições de ensino.

A LDB de 1996 altera o status da Arte na educação. O ensino de arte passa a ser considerado obrigatório em todos os níveis de educação, deixando de ser apenas atividade para se constituir enquanto área de conhecimento (André, 2008). De acordo com Pimenta (2013), com a LDB de 1996 as escolas teriam 10 anos para se adequar às exigências de que todo professor da rede básica de ensino deveria ter formação superior. Mas as mudanças reais surgiram só em 2002 com as diretrizes curriculares nacionais para a formação de professores.

Em 2008, a LDB de 1996 é alterada e o ensino de música passa a ser obrigatório na educação básica. Tal alteração gerou uma série de confusões a respeito de sua aplicabilidade 
no currículo escolar. De fato, a lei não institui o ensino de música enquanto disciplina independente. Os conteúdos de músicas poderiam ser ministrados no escopo do componente curricular Arte, desde que por um professor específico da área (Gomes \& Nogueira, 2008). No entanto, o que de fato parece ter ocorrido, mais uma vez, era a utilização de capital humano já existente nas instituições, com novas contratações em número que não atendia às demandas reais. A mesma exigência de formação não existia para os professores das outras linguagens artísticas, dentre elas, o teatro.

No que tange ao teatro, a "primeira legislação para o ensino superior na área teatral foi o Parecer no 608/65 da Câmara do Ensino Superior - CFE, que fixou currículos para os cursos de Direção, Cenografia e Professorado em Arte Dramática" (Pimenta, 2013, p. 397). De acordo com o parecer, os cursos de Cenografia e Direção Teatral eram ofertados com carga horária útil de 2160 horas, em três anos, enquanto que a formação no Professorado em Arte Dramática exigia o acréscimo de 720 horas a esse montante.

Em 1997, tem-se o advento dos Parâmetros Curriculares Nacionais para o Ensino da Arte, que, embora não se configure como obrigatoriedade de adesão por parte das instituições de ensino, se tornou a mais efetiva referência das escolas para a constituição de seus currículos de Arte. No PCN-Arte, três eixos de saberes são atribuídos ao ensino de teatro: 1 - teatro como expressão e comunicação; 2 - teatro como produção coletiva; 3 - teatro como produto cultural e de apreciação estética (Brasil, 1997). Igualmente, as outras linguagens artísticas aparecem como eixos de conhecimento com especificidades. Entretanto, a atuação profissional ainda é voltada para a polivalência. No Referencial Curricular Nacional para Educação Infantil (Brasil, 1998), o teatro aparece como estratégia de ensino para desenvolvimento de experiência direta das crianças, por meio de visitas a espaços teatrais e assistência de espetáculos, mas não recebe maior atenção enquanto área de conhecimento ou eixo de conhecimento de e em Arte. O foco da presença da arte no documento sobre a educação infantil se volta para as artes visuais e para a música.

Já em 2004, com a Resolução CNE/CES 4, são aprovadas as Diretrizes Curriculares Nacionais do Curso de Graduação em Teatro (Pimenta, 2016). O artigo $4^{\circ}$ da Resolução estabelece as competências e habilidades esperadas do graduado em teatro:

I - conhecimento da linguagem teatral, suas especificidades e seus desdobramentos, inclusive conceitos e métodos fundamentais à reflexão crítica dos diferentes elementos da linguagem teatral;

II - conhecimento da história do teatro, da dramaturgia e da literatura dramática; III - domínio de códigos e convenções próprios da linguagem cênica na concepção da encenação e da criação do espetáculo teatral;

IV - domínio técnico e expressivo do corpo visando a interpretação teatral;

$\mathrm{V}$ - domínio técnico construtivo na composição dos elementos visuais da cena teatral;

$V I$ - conhecimento de princípios gerais de educação e dos processos pedagógicos referentes à aprendizagem e ao desenvolvimento do ser humano como subsídio para o trabalho educacional direcionado para o teatro e suas diversas manifestações; 
VII - capacidade de coordenar o processo educacional de conhecimentos teóricos e práticos sob as linguagens cênica e teatral, no exercício do ensino de Teatro, tanto no âmbito formal como em práticas não-formais de ensino;

VIII - capacidade de auto aprendizado contínuo, exercitando procedimentos de investigação, análise e crítica dos diversos elementos e processos estéticos da arte teatral (Grifos nossos).

No mesmo documento, os conhecimentos a serem propiciados aos graduandos são divididos em três diferentes eixos:

Art. $5^{\circ} \mathrm{O}$ curso de graduação em Teatro deve assegurar o perfil do profissional desejado, a partir de conteúdos e atividades que atendam aos seguintes eixos interligados de formação:

I - Conteúdos Básicos: estudos relacionados com as Artes Cênicas, a Música, a Cultura e a Literatura, sob as diferentes manifestações da vida e de seus valores, bem assim com a História do Espetáculo Teatral, a Dramaturgia, a Encenação, a Interpretação Teatral e com a Ética Profissional;

II - Conteúdos Específicos: estudos relacionados com a História da Arte, com a Estética, com a Teoria e o Ensino do Teatro, além de outros relacionados com as diferentes formas de expressão musical e corporal, adequadas à Expressão Teatral e às formas de Comunicação Humana;

III - Conteúdos Teórico-Práticos: domínios de técnicas integradas aos princípios informadores da formação teatral e sua integração com atividades relacionadas com Espaços Cênicos, Estéticos, Cenográficos, além de domínios específicos em produção teatral, como expressão da Arte, da Cultura e da Vida.

Como se pode perceber, ainda que se espere do graduado em teatro conhecimentos sobre os processos educacionais e de ensino-aprendizagem, os eixos de formação obrigatórios não incluem o campo educacional. Ainda que a formação de que trata a resolução seja voltada para o bacharelado, a frequente confusão entre finalidades de formação do bacharelado e da licenciatura também podem ser observadas nesse documento oficial. Este equívoco sofre finalidades de formação e os eixos de conhecimento não se restringem à formação em bacharelado. Segundo (Junqueira \& Manrique, 2015, p. 630), “O Parecer CNE/CP 009/2001 afirma, ainda, que os programas de formação de professores no Brasil mantêm um caráter que, predominantemente, preserva o formato $3+1$, inspirado no modelo da racionalidade técnica", a que em outro artigo dos autores deste texto se chamou de "bacharelização das licenciaturas" (Gonçalves \& Sampaio, 2016). Mesmo que algumas licenciaturas não deixem mais os conhecimentos educacionais, pedagógicos e de desenvolvimento afetivo-cognitivo humano para o último ano, a cisão entre conteúdos específicos da área e conteúdos nomeados como pedagógicos ainda se mantêm em muitos contextos de formação de professores na atualidade.

Ao contrário da cisão entre conteúdos pedagógicos e específicos prevalentes no modelo 3+1, a Resolução CNE/CP 2/2015, alterada pela Resolução CNE/CP 9/2017, prevê articulação e interdependência entre esses dois campos de saberes na formação docente. A 
resolução prevê a formação inicial de professores para o ensino básico organizada a partir de três eixos:

I - núcleo de estudos de formação geral, das áreas específicas e interdisciplinares, e do campo educacional, seus fundamentos e metodologias, e das diversas realidades educacionais [...]

II - núcleo de aprofundamento e diversificação de estudos das áreas de atuação profissional, incluindo os conteúdos específicos e pedagógicos, priorizadas pelo projeto pedagógico das instituições, em sintonia com os sistemas de ensino [...] III - núcleo de estudos integradores para enriquecimento curricular (p. 9-10).

Em 2005, com o Parecer CNE/CEB Nº: 22, a disciplina educação artística foi substituída pelo Ensino de Arte. Todavia, só em 2016, com a Lei no 13.278 , que altera o parágrafo $6^{\circ}$ do artigo 26 da Lei no 9.394, de 20 de dezembro de 1996, e fixa as diretrizes e bases da educação nacional, referente ao ensino da arte, que o ensino das quatro linguagens artísticas: teatro, dança, música e artes visuais se tornam obrigatórias para a educação básica brasileira. Outra vez a mudança gera equívocos na interpretação da Lei. Não se trata da obrigatoriedade de se of erecer as quatro linguagens como disciplinas independentes, mas sim de ofertar, no escopo do componente curricular arte, as quatro linguagens, na mesma direção do que já acontecia com o ensino de música. Ainda que se pretenda que cada uma das linguagens seja ministrada por um professor com formação específica, o que se tem majoritariamente é um professor formado em uma das linguagens e que assume a responsabilidade por ministrar aulas sobre conteúdos das outras três linguagens artísticas. Em suma, e não se está asseverando aqui a necessidade de retorno à formação polivalente em arte, o que se tem na prática é a formação especializada para atuação polivalente.

Mais recentemente, as discussões a respeito da Base Nacional Comum Curricular (BNCC), já prevista na constituição de 1988, cuja versão final data de 2017, preveem que a arte seja presente na educação básica desde seis dimensões interdependentes:

Criação: refere-se ao fazer artístico, quando os sujeitos criam, produzem e constroem. Trata-se de uma atitude intencional e investigativa que confere materialidade estética a sentimentos, ideias, desejos e representações em processos, acontecimentos e produções artísticas individuais ou coletivas. Essa dimensão trata do apreender o que está em jogo durante o fazer artístico, processo permeado por tomadas de decisão, entraves, desafios, conflitos, negociações e inquietações.

Crítica: refere-se às impressões que impulsionam os sujeitos em direção a novas compreensões do espaço em que vivem, com base no estabelecimento de relações, por meio do estudo e da pesquisa, entre as diversas experiências e manifestações artísticas e culturais vividas e conhecidas. Essa dimensão articula ação e pensamento propositivos, envolvendo aspectos estéticos, políticos, históricos, filosóficos, sociais, econômicos e culturais. 
Estesia: refere-se à experiência sensível dos sujeitos em relação ao espaço, ao tempo, ao som, à ação, às imagens, ao próprio corpo e aos diferentes materiais. Essa dimensão articula a sensibilidade e a percepção, tomadas como forma de conhecer a si mesmo, o outro e o mundo. Nela, o corpo em sua totalidade (emoção, percepção, intuição, sensibilidade e intelecto) é o protagonista da experiência.

Expressão: refere-se às possibilidades de exteriorizar e manifestar as criações subjetivas por meio de procedimentos artísticos, tanto em âmbito individual quanto coletivo. Essa dimensão emerge da experiência artística com os elementos constitutivos de cada linguagem, dos seus vocabulários específicos e das suas materialidades.

Fruição: refere-se ao deleite, ao prazer, ao estranhamento e à abertura para se sensibilizar durante a participação em práticas artísticas e culturais. Essa dimensão implica disponibilidade dos sujeitos para a relação continuada com produções artísticas e culturais oriundas das mais diversas épocas, lugares e grupos sociais.

Reflexão: refere-se ao processo de construir argumentos e ponderações sobre as fruições, as experiências e os processos criativos, artísticos e culturais. É a atitude de perceber, analisar e interpretar as manifestações artísticas e culturais, seja como criador, seja como leitor (BNCC, Brasil, 2017, p. 152-153).

A BNCC, ainda que reconheça as especificidades de cada linguagem artística, assevera a necessidade de que a experiência em arte não seja estanque, senão articulada entre linguagens, que é o modo mesmo da pessoa experimentar as coisas do mundo. Nessa direção, as seis dimensões explicitadas anteriormente são comuns a todas as linguagens artísticas no contexto escolar e devem ser igualmente propiciadas e incentivadas. Isto é, além das quatro unidades temáticas: teatro, dança, música e artes visuais, o documento propõe uma quinta área temática intitulada Artes Integradas. A questão que se coloca aqui é: se a formação do professor é específica em uma linguagem artística, e se, no mais das vezes, as escolas possuem um ou dois professores de arte, como o profissional poderá atender às especificidades das quatro linguagens e ainda propor práticas e discussões que as integrem no escopo do eixo temático Artes Integradas? O único caminho que se tem, desde o ponto de vista dos autores, para solver esta questão é que cada instituição de ensino tenha professores formados nas quatro linguagens artísticas. Realidade que está longe de se efetivar no Brasil. A situação se torna ainda pior quando se constata, como já se fez neste texto, que a formação de professores das linguagens artísticas tende, ainda, a se dar em contextos de "bacharelização das licenciaturas" (Gonçalves \& Sampaio, 2016), tema que interessa particularmente às análises que se apresentam na sequência deste texto.

Após esse breve panorama da formação e atuação de professores de teatro (e de arte de modo mais amplo), no que se segue, apresentam-se as análises interpretativas dos conteúdos documentais das cinco instituições que reformularam seus documentos no período focal de interesse desta pesquisa. 


\section{Caso UFAL}

Neste primeiro estudo de caso tomam-se como referência os PPCs elaborados nos anos de 2006 e 2014 para a Licenciatura em Teatro da Universidade Federal de Alagoas. No documento de 2006, as disciplinas cujos títulos se referiam à palavra corpo e suas derivações ${ }^{3}$ são: "Expressão Corporal" e "Corpo e Movimento". Já no documento de 2014, tem-se como "componentes sobre o corpo" um conjunto de disciplinas sequenciadas (com pré-requisitos): Estudos do movimento I, II, III e IV, sendo as três primeiras obrigatórias e a última eletiva.

A ementa da disciplina "expressão corporal" está assim descrita no documento:

Investigação das possibilidades do uso do corpo como instrumento expressivo. Afirmação corporal e domínio de postura. Percepção do corpo como via de comunicação. Concentração, tensão, relaxamento e sensibilização. Noção global e segmentada do movimento. Conscientização das potencialidades expressivas e ampliação dos limites corporais (UFAL, 2006, p. 08, grifos nossos).

De acordo com os trechos destacados no texto (instrumento, domínio de postura, conscientização das possibilidades expressivas), a disciplina parece se enquadrar na categoria de análise instrumentalização. $\mathrm{O}$ que distancia a ementa da categoria de análise ensino é a ausência de qualquer explicitação de que se trate de estudos prático-metodológicos para a atividade corporal na educação. Desta forma, se supõe que a disciplina seja uma etapa de instrumentalização que antecede a criação artística. Pensamento bastante recorrente nas práticas teatrais: os estudos dos "componentes sobre o corpo" têm por finalidade, no mais das vezes, propiciar contextos de preparação corporal para a atividade de criação.

Já a disciplina "Corpo e Movimento" pretendia

Reflexões e práticas que venham possibilitar ao aluno uma melhor compreensão e conhecimento sobre seu corpo e os outros corpos, suas possibilidades de movimento, linguagem corporal e expressão em relação a criatividade, seu valor e conceituação em diferentes culturas e momentos sócio-históricos. Suas relações com a mente, enfatizando a importância de saber observar, criar e expressar com os corpos (UFAL, 2006, p. 11, grifos nossos).

Diferentemente da disciplina anterior, "Corpo e Movimento" parece propor certa articulação entre as categorias criação e ensino, com maior destaque para a primeira das duas categorias. Isto pode ser observado pela articulação das palavras em destaque na ementa (conhecimento, criatividade, criar e expressar). Ainda assim, não está claro na disciplina o vínculo da mesma com discussões a respeito da atuação do professor de teatro na educação básica. Essa, que pode se dar como uma meta tácita, igualmente pode não adentrar o escopo das metas dessa etapa da formação, apresentando-se desarticulada com o contexto futuro de atuação do profissional. Tal fato vai ao encontro do que se afirmou anteriormente neste texto: 
as licenciaturas no Brasil ainda sofrem da separação entre conhecimentos ditos específicos e conhecimentos ditos pedagógicos.

Já o conjunto das quatro disciplinas de "componentes sobre o corpo" se aproximam muito mais da categoria de análise criação, como pode ser observado nos destaques a seguir:

Estudos do Movimento I - A organização do corpo em movimento a partir da perspectiva da educação somática. Ações corporais e movimento estruturado. Corpo e criatividade.

Estudos do Movimento II - O espaço como categoria para a exploração criativa do movimento. As noções de orientação espacial e a ação cênica.

Estudos do Movimento III - A expressividade como categoria para exploração criativa do movimento. O tônus muscular, o ritmo e o desenho do movimento no espaço como elementos constitutivos da expressividade.

Estudos do Movimento IV - O relacionamento como possibilidade de desenvolvimento da criatividade e da ampliação do repertório de movimento. Estudos das relações com objetos e com companheiros em ações variadas de aproximar, afastar, tocar, transportar, etc. (UFAL, 2014, p. 88-91).

Quando se vê o conjunto sequencial das disciplinas, outra vez não aparece nas ementas relação com a categoria ensino. Ainda que a palavra educação apareça no conjunto dos documentos, ela está voltada para a educação somática, o que se adequa melhor à categoria instrumentalização. Aliás, a disciplina "Corpo e movimento III" se volta prioritariamente para a categoria instrumentalização. Nesse sentido, a mudança do PPC representou para o conjunto das disciplinas de "componentes sobre o corpo" maior ênfase para a categoria criação, distanciamento da categoria ensino e pulverização nas quatro disciplinas dos conteúdos relativos à categoria instrumentalização. A categoria criação ganha destaque no PPC do ano de 2014 inclusive por todas as disciplinas serem enquadradas dentro do eixo temático "Linguagem Teatral", como parte principal do grupo temático "Poéticas do Corpo", que tem por finalidade "estudo do corpo humano como meio expressivo e comunicacional, em que a prática e a teoria são indissociáveis para a aprendizagem realizada através de Abordagem Triangular" (UFAL, 2016, p. 62).

No conjunto das referências bibliográficas das disciplinas dos "componentes sobre o corpo", a situação se repete em relação às ementas. Algumas referências que tinham por foco a categoria ensino ${ }^{4}$ são excluídas no documento de 2016 e são acrescidas referências sobre a categoria $c r i a c ̧ \tilde{a} o^{5}$. Não se pode negar que tenha sido feita certa atualização das referências bibliográficas. Entretanto, o ônus de tal atualização recai sobre o distanciamento das propostas da categoria ensino. Textos de e estudos sobre Rudolf Laban $^{6}$ são as principais referências dos "componentes sobre o corpo", não só nos PPCs da UFAL como em todos os que foram analisados no decorrer dos dois anos de pesquisa ${ }^{7}$.

\section{Caso UFG}


Neste segundo estudo de caso tomam-se como referência os PPCs elaborados nos anos de 2004 e 2015 para a Licenciatura em Teatro da Universidade Federal de Goiás. No documento de 2004 as disciplinas do conjunto de "componentes sobre o corpo" são: Artes do Corpo I, II, III e IV, enquanto que no PPC de 2015, apenas as três primeiras disciplinas são ofertadas. Por se tratarem de disciplinas sequenciais em ambos os casos, as análises serão feitas pelo conjunto de ementas. No documento de 2004 as ementas estão assim descritas:

Artes do corpo 1 - Compreensão do corpo para o ator e Consciência corporal da anatomia pessoal e geral. Percepção e Dinâmica postural: estados de tensão e relaxamento, musculatura profunda, respiração completa e centro gerador do movimento. Desenvolvimento de base e eixo com vistas ao aprimoramento do movimento integrado e integrador. Introdução à improvisação.

Artes do corpo 2 - Preparação Corporal. Desenvolvimento do Estado de Presença Cênica e Memória Corporal. Percepção corporal individual e coletiva: identificação e transformação de tensões pessoais, expansão e dilatação dos movimentos. Estudo e construção de um aquecimento pessoal. Pesquisa e Produção de movimentos pessoais. Estudo do movimento humano cênico. Ações Físicas e Improvisações individuais e coletivas.

Artes do corpo 3 - Repertório Gestual. Mímeses corpóreas e sotaques corporais. Preparação individual e coletiva. Investigação e desenvolvimento do repertório gestual pessoal. Formação da fisicalidade cênica baseada na observação externa em sincronia com a auto observação. Estudo do corpo por diversos encenadores. Composições de frases gestuais.

Artes do corpo 4 - Técnicas corpóreas nas diversas referências teatrais e escolas do movimento. Investigação das construções e organizações corporais para a cena. Composições próprias individuais e coletivas. Pesquisa de repertório de movimentos na criação de personagens (UFG, 2004, p. 36, grifos nossos).

Como se pode observar, os trechos em destaque apontam para uma preocupação maior com a criação (preparação corporal, pesquisa e produção de movimentos pessoais, estado de presença cênica, improvisações, mímeses corpóreas, físicalidade cênica, estudo do corpo por diversos encenadores, construções de organizações corporais para a cena, composições e criação de personagens), seguida dos processos de instrumentalização (consciência corporal, dinâmica postural, desenvolvimento de base e eixo). De acordo com essa análise, a disciplina "Artes do Corpo I" se adequa à categoria instrumentalização, enquanto as outras três à categoria criação. No todo das ementas dos "componentes sobre o corpo" não há qualquer menção que leve a supor articulação com a categoria ensino.

As disciplinas constantes do PPC de 2015 possuem o seguinte ementário:

Artes do corpo I - Percepção, consciência do corpo e de suas potencialidades de movimento. Introdução às técnicas de educação somática. Introdução ao estudo do movimento. Improvisação e pesquisa de movimento.

Artes do corpo II - Percepção e consciência do corpo em movimento: consciência das imagens e da expressividade do corpo no espaço. Percepção espaço- 
temporal, peso, apoio, fluência, dinâmicas e conectividade. Presença cênica, disponibilidade e espontaneidade. Improvisação, pesquisa de movimento e composição cênica. Observação e análise do movimento. Leituras do corpo na arte contemporânea.

Artes do Corpo III - Percepção e consciência do corpo em movimento. Percepção e consciência das imagens e da expressividade do corpo no espaço. A construção da dramaturgia do corpo. Jogo como elemento de composição cênica. Organização do movimento: ação e construção de sentido. Ação física e ação vocal. Improvisação, pesquisa de movimento e composição cênica. (UFG, 2015, p. 36, grifos nossos)

A análise das ementas faz supor uma articulação maior entre as categorias instrumentalização e criação, do que aquela observada no documento de 2004. Se antes a categoria instrumentalização estava explicitada apenas na primeira disciplina do conjunto, agora aparece em todas as três (Artes do corpo I: consciência do corpo, educação somática; Artes do corpo II: consciência do corpo, percepção espaço-temporal; Artes do corpo III: consciência do corpo em movimento, organização do movimento). Por sua vez, as referências à criação também estão contempladas em todas as ementas (Artes do corpo I: Improvisação e pesquisa do movimento; Artes do corpo II: imagens e expressividade do corpo, presença cênica, improvisação, composição cênica; Artes do corpo III: dramaturgia do corpo, composição cênica, improvisação).

Dois fatores merecem destaque. Primeiro, novamente não se encontra no ementário dos "componentes sobre o corpo" referência direta com a categoria ensino. E houve uma drástica redução da carga horária total desses componentes. O conjunto das disciplinas em 2004 apresentava carga horária igual a 224 horas de atividades, enquanto que no documento de 2015 constam apenas 144 horas de atividades. Tal fato representa uma redução de quase $40 \%$ da carga horária inicial.

Quanto às referências bibliográficas, a mudança mais expressiva está na presença marcante, no documento de 2015, da educação somática ${ }^{8}$. Algo que não se via no PPC de 2004. Do total de 20 referências bibliográficas, 07 estão direta ou indiretamente vinculadas à educação somática. Outra vez não se encontra na bibliografia do ementário obras que indiquem articulação explícita sobre os "componentes sobre o corpo" e a categoria ensino (de teatro na educação básica).

\section{Caso UFGD}

Neste terceiro estudo de caso tomam-se como referência os PPCs elaborados nos anos de 2009 e 2014 para a Licenciatura em Artes Cênicas da Universidade Federal da Grande Dourados. No primeiro documento, as disciplinas de "componentes sobre o corpo" são: Técnicas e Poéticas do Corpo I, II, III e IV, sendo as três primeiras obrigatórias e a última eletiva. Já no documento de 2014, além das disciplinas anteriores foi acrescida a disciplina: 
Ateliê Corporal. Diferente do que se observou no caso anterior, portanto, houve aumento da carga horária total dos "componentes sobre o corpo".

Por serem disciplinas sequenciais e que não sofreram alteração com a reestruturação do PPC, serão abordados os "componentes sobre o corpo" do documento de 2009 e de 2014 simultaneamente, como um conjunto de ementas.

Técnicas e Poéticas do Corpo I - Estudo técnico corporal; estudo dos temas de movimento, consciência corporal e a análise de ações corporais, privilegiando o reconhecimento da estrutura óssea e muscular, assim como os processos fisiológicos, as estruturas anatômicas e os processos motores envolvidos no movimento. Estudo poético corporal; estudo do corpo e ancestralidade e suas poéticas por meio de pesquisa de campo e análise de ações corporais. Elaboração e criação de laboratórios de movimento para execução de processos de criação em exercícios cênicos.

Técnicas e Poéticas do Corpo II - Estudo técnico corporal; Estudo e análise do corpo nas danças, lutas e jogos populares brasileiros. Princípios técnicos das lutas e jogos: capoeira, maculelê, jogos de regra e outras manifestações cênicas populares. Estudo poético corporal; introdução a etnocenologia, pesquisa de campo e entrevistas. Identificação das poéticas para a construção do corpo cênico inspirado nas danças e nos saberes populares.

Técnicas e Poéticas do Corpo III - Estudo técnico corporal; aplicação da expressão no processo de treinamento físico do ator, conhecimento do próprio corpo e de sua capacidade criativa. Estudo do condicionamento motor para artistas cênicos e a criação por meio da exploração dos elementos do movimento da cena contemporânea. Estudo poético corporal; introdução ao estudo de processo de criação em Dança-Teatro; Tônus corporal e emoção. Relação entre som e movimento, entre palavra e gesto. Composição e gestualidade de personagens; relações com a dança-teatro (UFGD, 2009, p. 29, grifos nossos).

Técnicas e Poéticas do Corpo IV - Concepção de um processo técnico e poético em dança-teatro contemporânea, criação, produção e ação artística e cultural que resulte em uma performance a ser realizada com a comunidade externa (UFGD, 2009, p. 31, grifos nossos).

Os trechos em destaque no ementário revelam uma progressiva passagem do foco das disciplinas da instrumentalização para a criação. A primeira das disciplinas se volta prioritariamente para a instrumentalização (técnicas e poéticas do corpo I), enquanto que a última se volta em sua completude para a criação (técnicas e poéticas do corpo IV). As duas disciplinas intermediárias compreendem aspectos tanto da categoria instrumentalização quanto da categoria criação, de modo articulado entre si. Aspecto a ser ressaltado, de que já falamos anteriormente, é que as propostas de instrumentalização do referido ementário servem como base para iniciativas de criação. O que permite supor que a categoria instrumentalização não compreende em si um eixo de conhecimento, mas sim, a construção de ferramentas e instrumentos a serem usados posteriormente na criação cênica. Esta última categoria reconhecidamente aceita como eixo independente de conhecimento. Ou seja, 
instrumentalizar requer sempre o complemento para, enquanto que criar se encerra em si mesmo. Outra vez não se percebe explicitada nas ementas a relação entre instrumentalização, criação e ensino.

A disciplina acrescida no documento de 2014, Ateliê Corporal, apresenta a seguinte ementa: "Consciência corporal. Percepção e consciência do corpo em movimento. Coordenação motora e rítmica. Percepção dos sentidos, espacialidade e expressão vocal" (UFGD, 2014, p. 29, grifos nossos). Claramente a disciplina, diferente das demais analisadas, está estritamente voltada para a categoria instrumentalização. Como pré-requisito para as demais disciplinas, ela se torna a base do que culminará nos processos de criação corporal ao longo dos semestres do curso. Tal fato ratifica a hipótese anterior de que instrumentalização é sempre para alguma atividade além da que se propõe.

Quanto às referências bibliográficas, nos dois documentos as obras se agrupam em três conjuntos: escritos sobre corpo e criação em teatro ${ }^{9}$; escritos sobre corpo e criação e dança ${ }^{10}$; escritos sobre corpo, mito e culturas populares ${ }^{11}$. A única obra que se volta explicitamente para o ensino é do campo da dança e não do campo do teatro ${ }^{12}$. Nesse sentido, as referências bibliográficas se equiparam à situação das ementas no que tange à relação entre instrumentalização, criação e ensino.

\section{Caso UnB}

Neste quarto estudo de caso tomam-se como referência os PPCs elaborados nos anos de 2014 e 2016 para a Licenciatura em Artes Cênicas da Universidade de Brasília. As alterações realizadas no documento não apresentam alterações no que se refere aos "componentes sobre o corpo". São três as disciplinas constantes nos documentos e que interessam neste texto: Movimento e Linguagem 1, 2 e 3. Como nos casos anteriores, por se tratarem de disciplinas sequenciais será feita análise simultânea do ementário das três disciplinas.

Movimento e Linguagem 1 - Linguagem e Técnica: - Princípios da consciência corporal e da análise do movimento. Introdução ao desenvolvimento rítmico $e$ psicomotor. Identificação de potencialidades e limites individuais (UnB, 2014, p. 21; UnB, 2016, p. 34, grifos nossos).

Movimento e Linguagem 2 - Técnica e Estética: Exercícios técnicos e análise do movimento. Desenvolvimento rítmico e de habilidades. Aplicação do vocabulário (UnB, 2014, p. 27; UnB, 2016, p. 42, grifos nossos).

Movimento e Linguagem 3 - Estética e Diversidade: Aprimoramento de habilidades e domínio do movimento. Aplicação do vocabulário gestual e aplicação dos estudos abordados na criação expressiva (UnB, 2014, p. 31; UnB, 2016, p. 46, grifos nossos).

Na mesma direção do que foi apontado sobre os PPCs da UFGD, as ementas e os destaques apresentados indicam progressiva passagem da instrumentalização à criação. Tal fato pode ser notado pelos recortes temáticos que acompanham as disciplinas. No recorte 
temático da disciplina Movimento e Linguagem 1 aparece a palavra Técnica e no ementário as expressões: "consciência corporal" e "desenvolvimento psicomotor". Não há indicação de referências à categoria criação. Já na disciplina Movimento e Linguagem 2 encontra-se no subtítulo tanto a palavra técnica quanto a palavra estética, indicando equilíbrio entre a instrumentalização e a criação. Por fỉm, na disciplina Movimento e Linguagem 3, no subtítulo já não aparece mais referência à técnica, e a disciplina está marcadamente voltada para a criação, como aponta o trecho final da ementa, com o destaque "criação expressiva". Como já se indicou nas análises anteriores, também nesse caso não há explicitação de interesse na articulação entre instrumentalização, criação e ensino.

Assim como as ementas das disciplinas não sofreram alteração, também as referências bibliográficas não foram alteradas. As obras indicadas nas disciplinas se agrupam em três conjuntos: corpo e teatro ${ }^{13}$; corpo e dança ${ }^{14}$; corpo e educação somática ${ }^{15}$. Mas não há também entre as referências bibliográficas obras que tratem da intersecção entre instrumentalização, criação e ensino.

\section{Caso UNIRIO}

Neste quinto estudo de caso tomam-se como referência os PPCs elaborados nos anos de 2006 e 2013 para a Licenciatura em Teatro da Universidade Federal do Estado do Rio de Janeiro. Diferente das análises anteriores, escolheu-se focar naquilo que os documentos apresentam de diferente em relação às propostas já analisadas neste texto. Isto porque, dos cinco casos estudados, apenas neste caso aparecem indicações diretas da presença da categoria ensino nas ementas dos "componentes sobre o corpo", bem como a articulação daquela categoria com as categorias instrumentalização e criação. No documento de 2006 a disciplina que garante tal integração é "Movimento e Educação", enquanto que no documento de 2013 é "Movimento e Pedagogia". Para além dos elementos técnicos e de criação corporal, trabalhados nas disciplinas Expressão Corporal I, II, III e IV (UNIRIO, 2006), sendo as três últimas optativas, aquelas disciplinas de articulação pretendem:

Desenvolvimento de dois campos interligados e complementares: o primeiro relacionado aos fatores do movimento e o segundo de instrumentalização para aplicação desses conteúdos e daqueles trabalhados em Expressão Corporal I em propostas pedagógicas em que o corpo é o principal veículo de expressão e comunicação (UNIRIO, 2013, p. 75).

Na continuidade do documento, entretanto, há uma indicação de um claro recorte dessa articulação, que, se em princípio está pensada para o campo teatral, acaba se aproximando muito mais do ensino de dança, ao propor que, com as disciplinas Movimento e Educação (UNIRIO, 2006) e Movimento e Pedagogia (UNIRIO, 2013), se guie pelas proposições de Rudolf Laban, cujo trabalho esteve voltado para a criação em dança. Segundo o documento de 2013, a ementa de Movimento e Pedagogia prevê “Aplicação dos estudos da Teoria do 
Movimento de Rudolf Laban nas propostas pedagógicas onde o corpo é o principal veículo de expressão e comunicação" (UNIRIO, 2013, p. 94). Ou seja, ainda que haja explícita preocupação com a categoria ensino, o caminho escolhido para se estruturar as iniciativas propostas emerge de literatura do campo da dança. Tal fato pode ser comprovado pelas referências bibliográficas da disciplina, as quais constam no plano de disciplina, que integra o PPC de $2013^{16}$.

\section{Além e aquém dos casos: a formação de professores e o ensino de teatro}

Sobre a importância de se pensar os "componentes sobre o corpo" no contexto dessa pesquisa e na formação de futuros professores de teatro recorre-se à Strazzacappa (2001), a partir de quem se afirma que não há educação que não seja antes de tudo uma educação do corpo. Entretanto, quando se esquece dessa premissa, passa-se a pensar instrumentalização e criação com outros fins, que podem ser igualmente válidos, mas que acabam não enfatizando como se deveria esse princípio de que qualquer pedagogia resulta em alguma formação corpo-sensível da pessoa.

A educação do corpo, de que trata essa pesquisa, quando pensada a partir das características específicas da aula de teatro, se comparada às outras áreas de conhecimento escolar, deveria visar ao que André (2008) reconhece como a função primeira da arte, criar condições para que as pessoas experimentem alguma natureza de estranhamento de si e do mundo para si mesmo. Tal proposição vai ao encontro da ideia de que a teatralidade experimentada pela pessoa na aula de teatro deveria ser aquela que implica em outros modos de ser e estar no mundo (Ferreira; Hartmann; Machado, 2017). Afinal, como afirma Giovinazzo Junior (2017), formação é antes de tudo construir consciência a respeito de si e dos outros.

Cada pessoa é fenomelogicamente situada física e simbolicamente no mundo, portanto, um ser cultural. A consciência de si, de que trata Giovinazzo Junior, inclui, certamente, consciência da dimensão senciente, sem a qual as relações com o mundo, com a cultura, não poderiam existir nos moldes conhecidos e experimentados pelo ser humano. Nessa direção, De Marinis (2012) assevera que não há qualquer fenômeno cultural que esteja desvinculado da existência corporal de pessoas. Isto é, o corpo é constitutivo de qualquer fenômeno cultural e social que exista. Nesse sentido, a formação, enquanto consciência de si, deve ser, antes de tudo, consciência senciente de si-mesmo. Com isso se recuperaria a ideia grega de aprendiz enquanto alguém que "se ocupa de si" (Lima \& Minayo-Gomez, 2003).

$\mathrm{Na}$ esteira do exposto, a estética que deveria ser privilegiada na educação é aquela que se alia à ética. $\mathrm{O}$ que em outras palavras significa a estética que questiona os modos convencionais, geralmente hegemônicos e excludentes, de se habitar o mundo (Loponte, 2017). Formação estética essa que antes de tudo deve ser a consciência que emerge do questionamento dos sentidos e de suas construções habituais. Se, como pretende Eco (1997), a arte deve dar a ver a coisa como se fosse a primeira vez, o teatro na educação, deveria dar a ver para cada pessoa seu corpo como se fosse a primeira vez. Se as relações corporais não 
se alteram, dificilmente se alterará qualquer relação com o mundo. Se o trabalho em sala de teatro na educação básica caminhar nessa direção, pode-se afirmar que

[...] educadores e alunos empregam convenções que desafiam, resistem e desmantelam sistemas de privilégio criados pelos discursos dominantes e práticas discursivas da moderna cultura do ocidente. Dessa forma, a prática da ação dramática cria espaços e possibilidades para dar forma à consciência pós-moderna e pós-colonial, sensíveis à pluralidade, diversidade, inclusão e justiça social (Koudela \& Santana, 2005, p. 153).

O conhecimento sensível, fruto da consciência senciente de si, ao fim e ao cabo, é resultado da ampliação da textura corporal nos processos de construção de conhecimento, finalidade primeira da fenomenologia do corpo. O que vai à contramão da busca da escola novista do caráter disciplinar e instrumentalizador, strito sensu, das práticas corporais (Nobrega \& Tibúrcio, 2004). O que se espera, portanto, com as proposições de articulação entre as categorias instrumentalização, criação e ensino, no contexto da inserção do teatro como parte da disciplina obrigatória Arte na educação básica, e para o que o licenciado em teatro deve estar preparado, é

(...) a experimentação lúdica e intencional de si mesmo de modo diverso daqueles recorrentes no âmbito da vida cotidiana da pessoa: alteridade de si-mesmo para si-mesmo. A passagem da simples experimentação para a experimentação em termos de teatralidade está no fato de que ela é, em certo sentido, direcionada para um outro: quer seja o professor ou outro aluno, quer seja para si mesmo em forma de distanciamento, esta última perspectiva é a mais central nos nossos interesses (Sampaio, 2017, p. 03).

\section{Considerações do percurso de pesquisa}

Os estudos de caso (análise de conteúdo documental) apresentados neste texto demonstram que de fato as licenciaturas no Brasil seguem, em sua maioria, como declarouse anteriormente, separando conteúdos específicos e pedagógicos, distribuindo cada um deles em componentes curriculares separadamente. Isto parece decorrer do modo como se criaram as licenciaturas no Brasil, como complementações aos bacharelados, e segundo o modelo 3 +1 (Pimenta, 2013).

Igualmente, percebe-se a raridade de obras que articulem instrumentalização, criação e ensino na área do teatro, no que tange aos "componentes sobre o corpo" e na direção declarada nesse texto. Esse fato já foi explicitado em artigo anterior (Conf. Gonçalves \& Sampaio, 2016) e ainda pode ser constatado mesmo com a atualização das referências que os novos PPCs aqui analisados propõem. De modo geral, verificou-se, ainda, que a bibliografia que serve de guia aos "componentes sobre o corpo" são provenientes de 3 campos de conhecimento: criação e técnica em teatro; criação e técnica em dança; educação somática. 
Um segundo grupo de referências está voltado para culturas populares, mitos e derivações. E o quinto grupo de referências se refere a textos da interface entre a filosofia e as artes.

Laban continua sendo a referência de maior recorrência, tanto nos PPCs analisados na primeira etapa desta pesquisa (Gonçalves \& Sampaio, 2016), quanto nos dados encontrados nos estudos de caso que aqui se apresentam. Das cinco obras com maior recorrência entre todos os PPCs reformulados encontram-se duas obras do autor (primeira ${ }^{17}$ e quarta ${ }^{18}$ com $^{2}$ maior recorrência) e uma outra sobre suas proposições (segunda ${ }^{19}$ de maior recorrência). Integram o grupo das cinco obras mais frequentes nos ementários dos "componentes sobre o corpo" uma obra sobre criação em teatro ${ }^{20}$ e outra sobre criação em dança ${ }^{21}$.

Com os resultados da pesquisa compreende-se que se faz necessário a elaboração de obras que articulem as três categorias de análise de que se utilizou nesta pesquisa, com fins de servir de referência às disciplinas sobre os "componentes sobre o corpo". Ainda que se saiba que o professor em sala de aula possa propor aproximações com o ensino de teatro, a ausência de apontamentos explícitos nas ementas sobre os "componentes sobre o corpo" pode levar as práticas em sala de aula a excluírem do escopo de suas discussões a finalidade primeira da formação de professores de teatro nas universidades brasileiras: docência no ensino básico. Ou seja, a progressiva e importante transformação do estatuto da arte na historicidade da legislação para formação superior e atuação do professor de teatro na educação básica, isto é, tendências pré-modernista (arte como técnica), modernista (arte como expressão); pós-modernista (arte como conhecimento) (Pimenta, 2016), não garante, por si só, que todos os eixos de conhecimento sejam articulados com a futura atuação do profissional graduado nas licenciaturas em teatro, como se pode constatar com os resultados desta investigação.

$\mathrm{Na}$ esteira da teoria da atividade, deve-se considerar que a professoralização só se completa na medida em que o formando passa das atividades de estudo para a prática docente (Dias \& Souza, 2017). Se as disciplinas de formação não apontam caminhos para que essa passagem se dê, o que se constrói para o licenciado é um abismo entre a universidade e a docência na educação básica. O que parece ser o epicentro dos tremores que levam a este abismo é o esquecimento de que é a partir da cultura da educação básica que deveria ser pensada qualquer formação superior de professores. Se a relação se inverte e se coloca à frente da cultura escolar a técnica teatral, por exemplo, já se terá dado o primeiro passo na direção da "bacharelização das licenciaturas" (Gonçalves \& Sampaio, 2016).

\section{Notas}

1. Resolução CNE/CP 2/2015. Diário Oficial da União, Brasília, 2 de julho de 2015 - Seção 1 - pp. 8-12.

2. Agradecemos a revisão atenta e carinhosa da Profa. Adriana dos Reis Martins, quanto aos dados apresentados neste tópico do artigo. Suas indicações foram de grande valia para o resultado final do texto.

3. Com fins de se facilitar escrita e leitura do texto, será atribuída a partir daqui a esse conjunto de disciplinas a nomenclatura "Componentes sobre o Corpo", que trata, portanto, das disciplinas que apresentam em seus nomes a palavra corpo e/ou movimento e/ou suas derivações tais como: corporal, corporeidade etc.. 
4. APIERRE, A. \& AUCOUTURIER, B. A Simbologia do Movimento: Psicomotricidade e Educação. Porto Alegre/SP/Brasil: Artes Medicas, 1986; BERGE, Y. Viver o seu corpo: por uma Pedagogia do movimento. Ed. Martins Fontes: São Paulo, 1981; LE BOUCH, J. A Educação pelo Movimento. Porto Alegre/RS/Brasil: Artes Medicas, 1985; STOKOE, P. \& HARF, R. Expressão Corporal na pré-escola. São Paulo: Ed. Summus, 1987.

5. Referências que integram a bibliografia de mais de uma das quatro disciplinas no documento de 2014 e que não constavam do documento de 2006: AZEVEDO, M. S. O papel do corpo no corpo do ator. São Paulo: Perspectiva, 2012; FERNANDES, C. O corpo em movimento: o sistema Laban/Bartenieff na formação e pesquisa em artes cênicas. São Paulo: Annablume. 2006; LABAN, R. Dança Educativa Moderna. São Paulo: Ícone, 1990; MACHADO, Mª A. A. P. Corpo do ator e comunicação. In Humus. Caxias do Sul: Sigrid Nora, 2004; OSTROWER, F. Criatividade e Processos de Criação. Rio de Janeiro: Ed. Vozes, 2011.

6. Rudolf von Laban (1879-1958) "dedicou sua vida ao estudo do movimento humano em seus significados e relações com o meio, resgatando os atos espontâneos pela dança e considerando a rotina de movimentos como restrição à expressividade do homem. Sua proposta de dança não considera apenas a graciosidade, beleza das linhas e leveza dos movimentos, mas a liberdade que possibilita ao homem se expor por seus movimentos e encontrar a auto-suficiência no próprio corpo" (SCARPATO, 2001, p. 60). Laban desenvolveu um sistema de notações para o movimento denominado Labanálise. Segundo Fernandes (2001, p. 10-11), "A Labanálise, uma linguagem de mapeamento corporal baseada em quatro categorias, pode ser comparada ao DNA, com suas quatro bases - Adenina, Guanina, Timina, Citosina responsáveis pelo código genético. No Sistema Laban, também organizado em forma de espiral, uma categoria interage com a outra em dupla hélice, reciprocamente provocando alterações e expansão das habilidades expressivas rumo ao "Domínio do Movimento".

7. Confira Gonçalves \& Sampaio, 2014.

8. BONSANELLO, D. P. Em pleno corpo: educação somática, movimento e saúde. Curitiba: Juruá, 2009; BERTAZZO, I. Espaço e Corpo - Guia de reeducação do movimento. São Paulo: SESC, 2004; COHEN, B. B. Sensing, feeling and action: the experimental anatomy of body-mind centering. Northampton, MA: Contact, 1993; FERNANDES, C. O corpo em movimento: o sistema Laban/Bartenieff na formação e pesquisa em artes cênicas. São Paulo: Annablume. 2006. QUEIROZ, L. Corpo, mente, percepção: movimento em BMC e dança. São Paulo: Annablume e FAPESP, 2009; STRAZZACAPPA, M. Educação somática e Artes Cênicas: princípios e aplicações. Campinas SP: Papirus, 2012; VISHNIVETZ, B. Eutonia - Educação do corpo para o ser. São Paulo: Summus Editorial, 2007.

9. ASLAN, O. O ator no século XX. São Paulo: Perspectiva, 1994; AZEVEDO, M. S. O papel do corpo no corpo do ator. São Paulo: Perspectiva, 2012; BURNIER, L. O. A arte do ator: da técnica à representação. Campinas, SP: Editora da UNICAMP, 2001; COHEN, R. Performance como linguagem: criação de um tempo-espaço de experimentação. São Paulo: Perspectiva, 2009; FERRACINI, R. Café com queijo corpos em criação. São Paulo: Hucitec, 2006; FO, D. \& RAME, F. Manual mínimo do ator. São Paulo: SENAC, 2011; STANISLAVSKI, C. A construção da personagem. Rio de Janeiro: Civilização Brasileira, 1976; STANISLAVSKI, C. A preparação do ator. Rio de Janeiro: Civilização Brasileira, 2012.

10. ANDRADE, M. de. Danças dramáticas do Brasil- $3^{\circ}$ Tomo, Belo Horizonte - Brasília: Editora Itatiaia Ltda., Instituto Nacional do Livro - Fundação Nacional Pró-memória, 1982; CYPRIANO, F. Pina Bausch. Cosac-Naify: São Paulo, 2005; FARO, A. J. Pequena história da dança. Rio de Janeiro: Zahar, 2011; FERNANDES, C. Pina Bausch e o Wuppertal Dança-Teatro. São Paulo: Ed. Annablume, 2007; HAAS, J. G. Anatomia da dança: guia ilustrado para o desenvolvimento de flexibilidade, resistência e tônus muscular. São Paulo: Manole, 2011; LABAN, R. Dança Educativa Moderna. São Paulo: Ícone Editora, 1990; LABAN, R. O Domínio do Movimento. São Paulo/SP/Brasil: Summus, 2004; NEVES, N. Klauss Vianna: estudos para uma dramaturgia corporal. São Paulo: Cortez, 2008; RODRIGUEZ, G. O bailarino Interprete pesquisador - Processo de Formação. Rio de Janeiro: FUNARBE, 1997; TADRA, D.; VIOL, R.; PRTOLAN, S.; MAÇANEIRO, S. Linguagem da dança. Curitiba: Ibpex, 2009; VIANNA, K. A dança. São Paulo, SP: Siciliano, 1991; WELLS, R. O corpo se expressa e dança. Rio de Janeiro: Francisco Alves, 1983.

11. ALMEIDA, R. de; PIMENTA, L.; CYPRIANO, A. Capoeira, dança e jogo da liberdade. São Paulo: Aori produções culturais, 2009; AYALA, M. \& AYALA, M. I. N. Cultura popular no Brasil: perspectiva de análise. São Paulo: Ática, 1995; BARTHES, R. Mitologias. São Paulo: Difel, 1985; CALDEIRA, S. O lamento da imperatriz. Rio de Janeiro: Ed. Annablume, 2009; CAMPBELL, J. O poder do mito. São Paulo: Palas Athena, 2003; CAMPBELL, J \& KUDLER, D. Mito e transformação. São Paulo: Ed. Agora, 2008; CASCUDO, L. C. Mitos brasileiros. Caderno de folclore no 6. Ministério da Educação e Cultura. Secretaria da Cultura. Fundação nacional da Arte - FUNARTE. Instituto Nacional do Folclore, 1976; CHEVALIER, J. \& GHEERBRANT, A. Dicionário de símbolos. Mitos, sonhos, costumes. Medina: João Paulo Subira, 1948; MEDINA, J. P. S. O brasileiro e seu corpo. Campinas: Papirus, 1987; MONTENEGRO, A. 
T. História oral e memória a cultura popular revisitada. São Paulo: Contexto, 2013; ROCHA, E. O que é mito. São Paulo: Brasiliense, 1991; SHAPIRO, H. L. Homem, cultura e sociedade. Rio de Janeiro: Fundo de Cultura, 1966.

12. SANTOS, I. F. Corpo e Ancestralidade: uma proposta pluricultural de dança-arte-educação. Salvador: EDUFBA, 2002.

13. AZEVEDO, M. S. O papel do corpo no corpo do ator. São Paulo: Perspectiva, 2012; BONFITTO, M. A Cinética do Invisível. São Paulo, Editora Perspectiva, 2009; CAMARGO, C. C. S. Corpo do Ator Metamorfoses Simulacros. São Paulo: Annablume/FAPESP, 1999; LOBO, L. \& NAVAS, C. Teatro do Movimento. Brasília: L.G. E Editora, 2003;

14. BERTAZZO, I. Cidadão Corpo: Identidade e Autonomia do Movimento. São Paulo: Summus Editorial, 1998; CORDEIRO, A. L. Método Laban. São Paulo: Art Editora, 1989; FUX, M. Dança, experiência da vida. São Paulo: Summus, 1983; GIL, J. Movimento Total - O Corpo e a Dança. São Paulo: Iluminuras, 2004; KATZ, H. Um, Dois, Três. A Dança é o Pensamento do Corpo. FID-Fórum Internacional de Dança, Editorial, 2005; LABAN, R. Dança Educativa Moderna. São Paulo: Ícone Editora, 1990; LABAN, R. O Domínio do Movimento. São Paulo/SP/Brasil. Summus, 2004; NEVES, N. Klauss Vianna Estudo para uma Dramaturgia Corporal. São Paulo: Cortez, 2008. RENGEL, L. Dicionário Laban. São Paulo: Annablume, 2003; SILVA, S. Poema dançando Gilka Machado e Eros Volúsia. Brasília: Editora da Universidade de Brasília, 2007.

15. ALEXANDER, G. Eutonia: Um Caminho para a Percepção Corporal. São Paulo: Ed Martins Fontes, 1993; BERTAZZO, I. Corpo Vivo - Reeducação do movimento. São Paulo: Edições SESC, 2015; BRIEGHEL, G. M. Eutonia e Relaxamento. São Paulo: Manole, 1987; BÉZIERS, M.-M. \& PIRET, S. A Coordenação Motora: aspecto mecânico da organização psicomotora do corpo. São Paulo: Summus, 1992; FELDENKRAIS, M. Consciência pelo Movimento. São Paulo: Summus, 1997; GELB, M. O aprendizado do corpo. São Paulo: Martins Fontes, 1987.

16. FERNANDES, C. O corpo em movimento: o sistema Laban/ Bartenieff na formação e pesquisa em artes cênicas. São Paulo: Annablume, 2002; LABAN, R. O domínio do movimento. São Paulo: Summus, 1978; LOBO, L. \& NAVAS, C. Arte da Composição: teatro do movimento. Brasília: LGE Editora, 2008; MIRANDA, R. O Movimento Expressivo. Rio de Janeiro: FUNARTE, 1980; MOMMENSOHN, M. \& PETRELLA, P. Reflexões sobre Laban, O mestre do Movimento. São Paulo: Summus, 2006.

17. LABAN, R. O Domínio do Movimento. São Paulo/SP/Brasil. Summus. 2004.

18. LABAN, R. Dança Educativa Moderna. São Paulo: Ícone Editora, 1990.

19. FERNANDES, C. O corpo em movimento: o sistema Laban/Bartenieff na formação e pesquisa em artes cênicas. São Paulo: Annablume. 2006.

20. AZEVEDO, M. S. O papel do corpo no corpo do ator. São Paulo: Perspectiva, 2012.

21. RODRIGUEZ, G. O bailarino Interprete pesquisador - Processo de Formação. Rio de Janeiro: FUNARBE, 1997.

\section{Referências}

ALMEIDA JUNIOR, José Simões. Reflexões acerca do estágio curricular na formação do professor licenciado em teatro. Educação em Revista, v. 29, n. 02, pp. 43-64, jun. 2013.

ANDRÉ, Carminda Mendes. Espaço Inventado: o teatro pós-dramático na escola. Educação em Revista, Belo Horizonte, n. 48, p. 125-141, dez. 2008.

Brasil. Ministério da Educação e do Desporto. Secretaria de Educação Fundamental. Referencial curricular nacional para a educação infantil / Ministério da Educação e do Desporto, Secretaria de Educação Fundamental. — Brasília: MEC/SEF, 1998.

BRASIL. Secretaria de Educação Fundamental. Parâmetros curriculares nacionais: arte / Secretaria de Educação Fundamental. - Brasília: MEC/SEF, 1997.

DE MARINIS, Marco. Corpo e corporeidade no teatro: da semiótica às neurociências. Pequeno glossário interdisciplinar. Revista Brasileira de Estudos da Presença, v.2, n. 1, pp. 42-61, jan./jun. 2012.

DEL BEN, Luciana. Sobre os sentidos do ensino de música na educação básica: uma discussão a partir da Lei $n^{\circ}$ 11.769/2008. Música em Perspectiva, Revista do Programa de Pós-Graduação em Música da Universidade Federal do Paraná, vol. 2 nº 1. Curitiba, 2009. 
DIAS, Marisa da Silva \& SOUZA, Neusa Maria Marques de. Contribuições para compreender a formação na licenciatura e na docência. Educação em Revista, n. 33, p. 01-24, 2017.

ECO, Humberto. A mensagem estética. In: ECO, Humberto. A estrutura ausente. São Paulo: Perspectiva, 1997, p. 51-66.

FERNANDES, Ciane. Esculpturas líquidas: a pré-expressividade e a forma líquida na dança educativa (pós) moderna. Cadernos Cedes, ano XXI, n.53, pp. 07-29, abril/2001.

FERREIRA, Taís; HARTMANN, Luciana; MACHADO, Marina Marcondes. Entre escola e universidade: dinossauros e caderninhos por uma dramaturgia encarnada. Revista Brasileira de Estudos da Presença, v.7, n. 1, p. 45-70, jan./abr. 2017.

GIOVINAZZO JUNIOR, Carlos Antonio. A formação profissional nos cursos de licenciatura e o exercício do magistério na educação básica: intenções, realizações e ambiguidades. Educar em Revista, Edição Especial, n. 1, pp. 51-68, jun. 2017.

GONÇALVES, Amanda Diniz \& SAMPAIO, Juliano Casimiro de Camargo. A corporeidade no ensino de teatro: para onde apontam os PPCs das licenciaturas em teatro das universidades federais brasileiras? Caderno de Pesquisa, São Luís, v. 23, n. 1, p. 95-106, jan./abr. 2016.

GOMES, Karina Barra \& NOGUEIRA, Sonia Martins de Almeida. Ensino de Arte na escola pública e aspectos da política educacional: contexto e perspectivas. Ensaio: aval. Pol. Publ. Educ, Rio de Janeiro, v. 16, n. 61, p 583-596, out./dez. 2008.

JUNQUEIRA, Sonia Maria da Silva \& MANRIQUE, Ana Lúcia. Reformas curriculares em cursos de licenciatura de matemática: intenções necessárias e insuficientes. Ciênc, Educ, Bauru, v. 21, n. 3, p. 623$635,2015$.

KOUDELA, Ingrid Dormien; SANTANA, Arão Paranaguá. Abordagens metodológicas do teatro na educação. Ciências Humanas em Revista, São Luís, v. 3, n. 2, 2005.

LIMA, Silvana Mendes \& MINAYO-GOMEZ, Carlos. Modos de subjetivação na condição aprendiz: embates atuais. História, Ciência, Saúde - Manguinhos, v. 10(3), p. 931-953, set.-dez. 2003.

LOPONTE, Luciana Gruppelli. Tudo isso que chamamos de formação estética: ressonâncias para a docência. Revista Brasileira de Educação, v. 22, n. 69, p. 429-452, abr.-jun., 2017.

MARTINS, Adriana dos Reis. O ensino de música no município de Palmas, após o advento da Lei 11.769/2008. Dissertação de Mestrado. Programa de Pós-Graduação em Música. Universidade Federal de Goiás, Goiânia, 2011.

NÓBREGA, Terezinha Petrucia \& TIBÚRCIO, Larissa Kelly de O. M. A experiência do corpo na dança Butô: indicadores para pensar a educação. Educação e Pesquisa, v. 30, n. 3, p. 461-468, set/dez, 2004.

PIMENTA, Rosana Aparecida. Arte, cultura e educação e a formação do professor em dança. Tese de Doutorado. Universidade Estadual Paulista "Júlio de Mesquita Filho", Instituto de Artes, São Paulo, 2016.

PIMENTA, Rosana Aparecida. Ensino Superior em Artes Cênicas: dança e teatro no Brasil. ENGRUPEdança, v. 4, n. 1, p. 396-402, 2013.

SAMPAIO, Juliano Casimiro de Camargo. A teatralidade de si-mesmo no ensino de teatro. Repertório, 2017 (prelo).

SCARPATO, Marta Thiago. Dança educativa: um fato em escolas de São Paulo. Cadernos Cedes, ano XXI, n. 53, pp. 57-68, abril/2001.

STRAZZACAPPA, Márcia. A educação e a fábrica de corpos: a dança na escola. Cadernos Cedes, ano XXI, $n^{\circ} 53$, p. 69-83, abri/2001.

UFAL. Projeto Pedagógico do Curso de Teatro Licenciatura. Maceió: Universidade Federal de Alagoas, 2006. 
UFAL. Projeto Pedagógico do Curso de Teatro Licenciatura. Maceió: Universidade Federal de Alagoas, 2014.

UFG. Projeto Pedagógico do Curso de Licenciatura em Teatro. Goiânia: Universidade Federal de Goiás, 2015

UFG. Projeto Político-Pedagógico do Curso de Artes Cênicas: Licenciatura e Bacharelado. Goiânia: Universidade Federal de Goiás, 2015.

UFGD. Projeto Político-Pedagógico do Curso de Graduação em Artes Cênicas: Licenciatura e Bacharelado. Dourados: Universidade Federal da Grande Dourados, 2009.

UFGD. Projeto Político-Pedagógico do Curso de Graduação em Artes Cênicas: Licenciatura e Bacharelado. Dourados: Universidade Federal da Grande Dourados, 2014.

UnB. Projeto Político-Pedagógico do curo de Licenciatura em Artes Cênicas. Brasília: Universidade de Brasília, 2014.

UnB. Projeto Político-Pedagógico do curo de Licenciatura em Artes Cênicas. Brasília: Universidade de Brasília, 2016.

UNIRIO. Projeto Político-Pedagógico do curso de Graduação de Licenciatura em Teatro. Rio de Janeiro: Universidade Federal do Estado do Rio de Janeiro, 2013.

UNIRIO. Proposta De Construção Do Projeto Político-Pedagógico: Tensões Entre Rupturas E Permanências - Curso de Graduação em Teatro Modalidade Licenciatura. Rio de Janeiro: Universidade Federal do Estado do Rio de Janeiro, 2006.

\section{Correspondência}

Amanda Diniz Gonçalves: É mestranda em Letras e Licenciada em Teatro pela Universidade Federal do Tocantins.

E-mail: gdinizamanda@gmail.com

Juliano Casimiro de Camargo Sampaio: É Professor da Licenciatura em Teatro e da Pós-Graduação em Letras da Universidade Federal do Tocantins.

E-mail: juliano.casimiro@uft.edu.br

Texto publicado em Currículo sem Fronteiras com autorização dos autores 